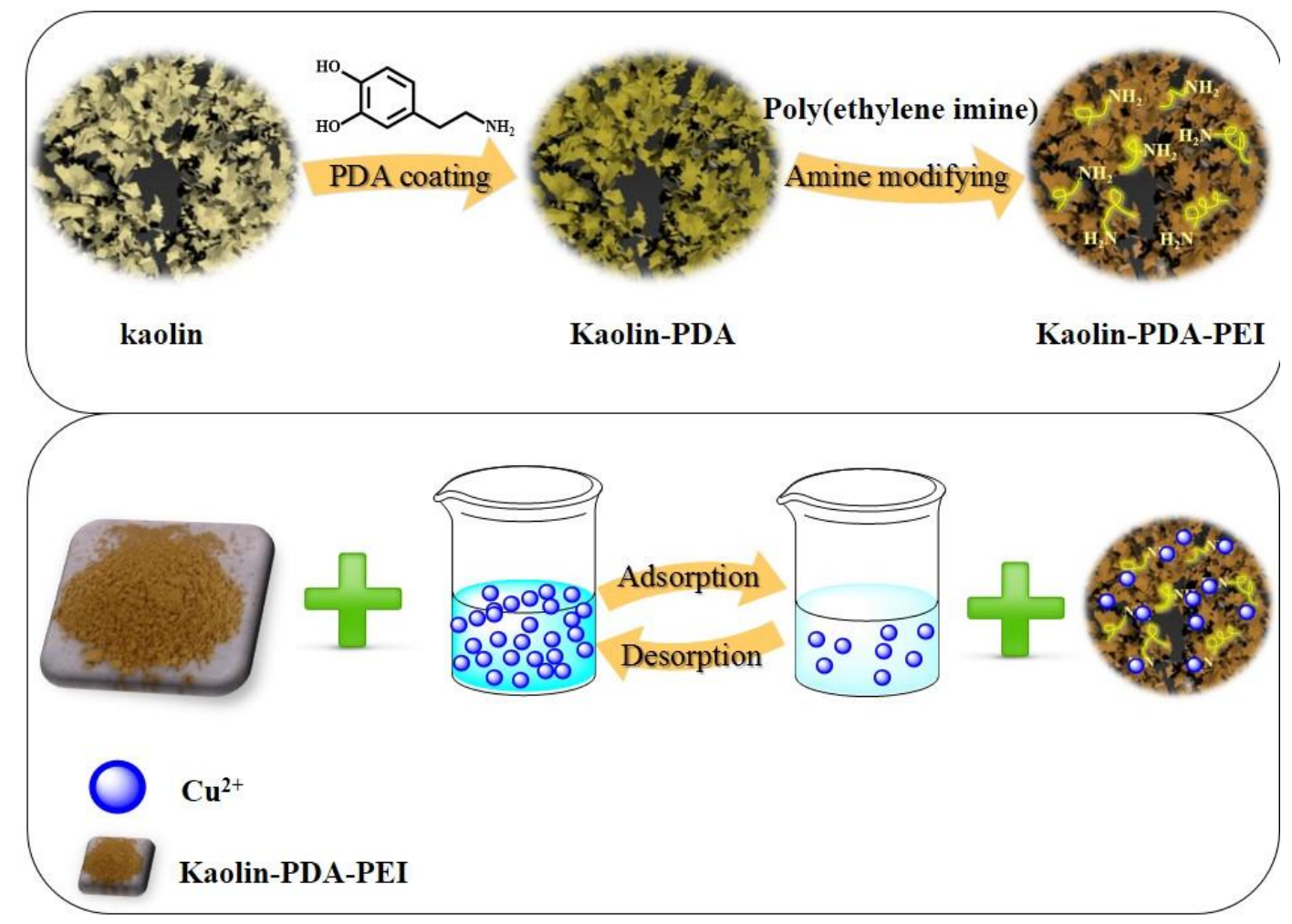

Amino groups functionalized Kaolin was facilely prepared via mussel inspired chemistry. The modified Kaolin exhibited much enhanced adsorption capability toward heavy metal ions. 


\section{Mussel inspired preparation of amine-functionalized Kaolin for effective removal of heavy metal ions}

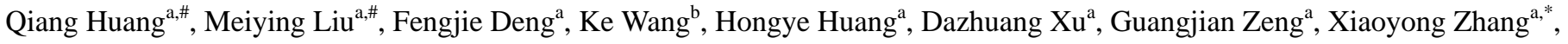
Yen $\mathrm{Wei}^{\mathrm{b}}$,*

a Department of Chemistry, Nanchang University, 999 Xuefu Avenue, Nanchang 330031, China

b Department of Chemistry and the Tsinghua Center for Frontier Polymer Research, Tsinghua University, Beijing, 100084, P. R. China.

\# These authors contributed equally to this work 


\section{Abstract}

Adsorption has been well regarded as a promising and efficient method for the removal of low concentration heavy metal ions in aqueous solutions. And kaolin has been considered as a kind of low cost and environment-friendly adsorbent for its abundant in nature. But the low adsorption capacity to heavy metal ions and severe aggregation in solution restrains its application. In this work, an environment-friendly adsorbent (denoted as Kaolin-PDA-PEI) was prepared based on mussel inspired chemistry and Michael addition reaction between high reaction activity of polydopamine (PDA) and polyethyleneimine (PEI), which was possesses a number of amine groups. The amine groups have displayed strong adsorption affinity towards copper ions. The successful modification of Kaolin by PDA and PEI was confirmed by a series of analyses, such as Fourier transform infrared spectroscopy, transmission electron microscopy, thermal gravimetry analysis and X-ray photoelectron spectroscopy. The effects of various parameters such as contact time, $\mathrm{pH}$, initial concentrations of copper ions and temperature on copper ion adsorption by Kaolin-PDA-PEI were investigated. Kaolin-PDA-PEI shows higher adsorption capacity as compared with the raw Kaolin. The kinetic adsorption data were analyzed using pseudo-first-order, pseudo-second-order and intraparticle diffusion model. The Langmuir isotherm and Freundlich isotherm equilibrium model were applied to adsorption isotherm data to find the better fit isotherm. The results showed that adsorption process was well fitted by Langmuir isotherm model. The values of thermodynamics constants such as entropy change $\left(\Delta S^{0}\right)$, enthalpy change $\left(\Delta H^{0}\right)$ and Gibbs free energy $\left(\Delta G^{0}\right)$ were also calculated. The results indicated that the adsorption process of Kaolin-PDA-PEI were endothermic and spontaneous. 


\section{Introduction}

Water, the base of life, has long been the requirement of human survival and economic development[1]. As the increasing development of economy, the demand of water increasing and the problem of water pollution has become more serious. Heavy metal pollution, defined as a kind of environment pollutions resulting from heavy metals or their compounds, is one of the most serious water pollutions.[2] Due to its bioaccumulation and toxicity, heavy metal pollution has made seriously effect on ecosystems and human beings [3, 4]. Among them, copper ions are one of the most commonly contained heavy metal ions in waste water. On the other hand, copper ions are one of the essential elements for human and play critical roles of human life process. However, the copper ions in high concentrations have toxic and adverse effects to living organism. Recent research shows that long-term drinking with high concentration copper $(>1 \mathrm{mg} / \mathrm{L})$ is associated with hemolytic anemia, hepatic failure, shock and death [5]. However, the concentration of copper ions in water generally increased with increasing industrial activities, which has become a potential threat to public health. Therefore, it is extremely urgent to explore corresponding solutions to reduce the copper ions in solution to keep the hygienic safety of drinking water $[6,7]$.

To date, several technologies, including coagulation, flocculation, membrane filtration, biological treatment, organic material and adsorption, have been developed and implemented for the purpose of removing heavy metal ions in solution. Adsorption has been considered as an efficient method to remove heavy metal ions from waste water because of its low cost and easy operation.[8] Currently, many adsorbents such as activated carbon [9, 10], sawdust [11], fly ash [12, 13], zeolite [14], chitosan in prawn shell [15], lignin [16], rubber leaf [17], manganese oxide coated sand [18], green algae [19], carbon nanotubes [20-24], graphene related materials [25, 26] and Kaolin [27] have been reported for removal of copper ions. Among them, Kaolin is considered as low cost natural clay that has been widely used in heavy metal ion removal. The physicochemical properties of Kaolin included small size, large specific surface area, and weak interlayer binding force are beneficial to the adsorption of heavy metal in solution. However, its severe agglomeration and low adsorption capacity in solution limits its applications severely. For example, its adsorption capacity to copper ions is only $0.67 \mathrm{mg} / \mathrm{g}$ [28]. Tavani EL et al [29] have investigated the amount of adsorbed chromium ions from tannery wastewater by natural Kaolin clay is only $0.108 \mathrm{mg} / \mathrm{g}$. Thus, numerous modification strategies, including high-temperature, coupling modification, surface grafting [30], radiation modification [31] and so on, have been developed to the modification of Kaolin to improve its dispersibility and adsorption capacity towards heavy metal ions. But many methods mentioned above suffer from defects such as high energy consumption, high cost, and high risk operation etc. Consequently, it is necessary to develop a facile, simple and effective strategy for Kaolin modification.

Mussel inspired chemistry is an emerging surface modification tool that has drawn greater attention in recent years.[32] It started originally by Herbert Waite's[33] research of marine mussel adhesion in 1980s. Subsequently, Lee at al [34, 35] carried out the further experimental research about dopamine self polymerization in an alkaline environment. They also demonstrated that mussel-inspired chemistry can be used as a universal and promising strategy for surface modification of various inorganic and organic materials.[34] Fei et al [36] have successfully synthesized varied thickness PDA coated carbon nanotubes based on 
dopamine self-polymerization and polymerization time-controlled. Yang et al[37] have developed a method to prepare a layer of protective shell on the surface of yeast cell combined with covalent conjugate and dopamine self-polymerization. Zhao et al[38] have prepared two-dimensional PDA/graphene oxide by self-assembly of dopamine monomers on graphene oxide surface for removal of radioactive element uranium. Zhang et al[39-51] have fabricated well-dispersed carbon nanotubes by surface modification with 3-mercapto-1-propanesulfonic acid sodium salt, normal dodecanethiol, polyethylene glycol and polymers through combination of mussel inspired chemistry and Michael addition reaction. On the other hand, the formation of PDA coating has also investigated by some groups. $[52,53] \mathrm{A}$ lot of parameters such as $\mathrm{pH}$, temperature and oxygen might influence the self polymerization of PDA. However, the detailed mechanism is still not clear for the complexity of self polymerization procedure.

In this study, we prepared an environment-friendly adsorbent combined with mussel inspiration and Michael addition reaction (Scheme 1). Kaolin was first coated with a thin layer of PDA coating via the self-polymerization of dopamine, and then PEI was conjugated with PDA coating through Michael addition reaction. The successful preparation of amine functionalized Kaolin was confirmed by a series of analyses. This prepared adsorbent was used to the removal of copper ions from waste water and the effect of contact time, $\mathrm{pH}$, contact temperature, and initial concentration of copper ions were studied. The adsorption kinetics and thermodynamics of the adsorption process were also investigated.

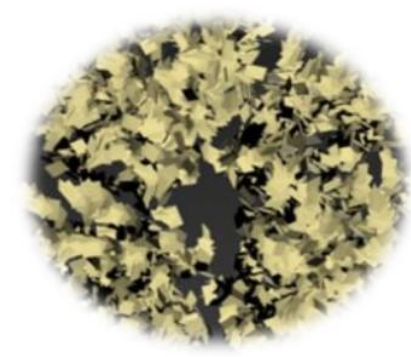

kaolin

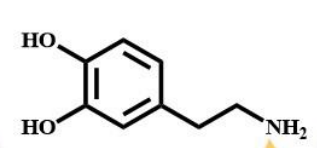

PDA coating

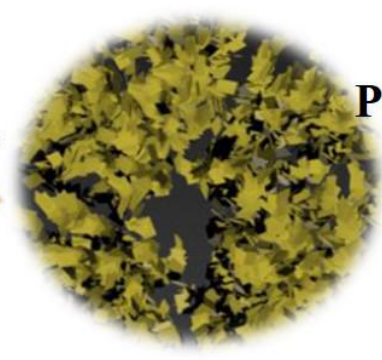

Kaolin-PDA
Poly(ethylene imine)

Amine modifying

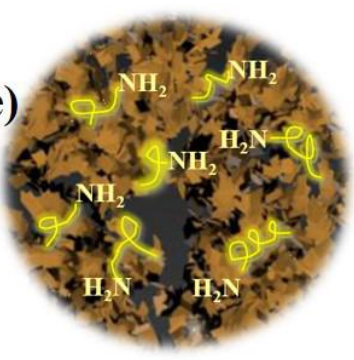

Kaolin-PDA-PEI

Scheme.1 Schematic diagram shows the preparation of Kaolin-PDA-PEI via combination of mussel inspired chemistry and Michael addition reaction.

\section{Experimental procedure}

\subsection{Materials and methods}

\subsubsection{Materials}

Kaolin $\left(\mathrm{Al}_{2} \mathrm{Si}_{2} \mathrm{O}_{9} \mathrm{H}_{4}\right)$ was purchased from Aladdin Industrial Co., Ltd. Polyethyleneimine (PEI) (molecular weight of $\left.800 \mathrm{Da}\right)$, copper nitrate trihydrate (>99.99\%) and bis-(cyclohexanone)-oxalyldihydrazone $(98.0 \%)$ used in this study were purchased from Aladdin Industrial Co., Shanghai, China. The dopamine hydrochloride (>98\%) was purchased from Sangon Co. and tris-(chydroxymethyl)-aminethane (Tris) (>99\%) was purchased from Tianjin Heowns Biochem.LLC.Co. 


\subsubsection{Preparation of Kaolin-PDA-PEI}

The surface funcitonalization of Kaolin with amine groups was performed according to previous study[54]. Briefly, 500 mg Kaolin and $500 \mathrm{mg}$ dopamine were dispersed into $100 \mathrm{~mL}$ alkaline buffer solution (10 mM Tris) in a flask. The mixture was constantly stirred at room temperature for $8 \mathrm{~h}$. After that, the mixture was centrifuged under $8000 \mathrm{r} / \mathrm{s}$ for 5 min and washed 3 times with deionized water. The product (named as Kaolin-PDA) was obtained via dried under vacuum at $353 \mathrm{~K}$. Then $500 \mathrm{mg}$ Kaolin-PDA and $500 \mathrm{mg}$ PEI were added into a flask with $100 \mathrm{~mL} 10 \mathrm{mM}$ Tris buffer solution and then dispersed by ultrasonicator for $10 \mathrm{mi}$ and stirred at room temperature for $8 \mathrm{~h}$. The obtained mixture was centrifuged under $8000 \mathrm{r} / \mathrm{s}$ for $5 \mathrm{~min}$, washed several times by deionized water and dried at $353 \mathrm{~K}$ for $4 \mathrm{~h}$.

\subsubsection{Characterization of Kaolin, Kaolin-PDA and Kaolin-PDA-PEI}

The chemical structural information of Kaolin and functionalized Kaolin were measured by Fourier transform infrared spectroscopy (Perkin-Elmer Spectrum 100 spectrometer) in the wave number range of 400-4500 $\mathrm{cm}^{-1}$ with a resolution of $1 \mathrm{~cm}^{-1}$. The elements of Kaolin were characterized by X-ray photoelectron spectroscopy by using VGESCALAB 220-IXL with Al Ka X-ray source $(1486.6 \mathrm{eV})$. The particle size and morphology characteristics of Kaolin were detected with a $100 \mathrm{KV}$ transmission electron microscopy (TEM, Hitachi-7650B). The thermo gravimetric analysis (TGA) was performed on a SDTQ600 thermo gravimetric analyzer at $20 \mathrm{~K} / \mathrm{min}$ under $100 \mathrm{~mL} / \mathrm{min}$ nitrogen flow.

\subsection{Absorption studies}

The adsorption performance of amine functionalized Kaolin was evaluated in the batch adsorption of copper ions. Adsorption kinetic experiments were conducted by a $50 \mathrm{~mL}$ sample tube containing $10 \mathrm{mg} / \mathrm{L}$ of copper ions and $10 \mathrm{mg}$ of adsorbents to determine the adsorption equilibration time at room temperature. The sample tube was placed on a vapor-bathing constant temperature vibrator and about $4 \mathrm{~mL}$ suspensions were taken from it at different time intervals of the adsorption reaction. The concentrations of copper ions after the adsorption was measured by the ultraviolet and visible spectrophotometer (purchased from Beijing Purkinje General Instrument Co.). Adsorption thermodynamics batch experiments were carried out at different temperature $(293,303,313,323$ and $333 \mathrm{~K})$ with same concentration, $\mathrm{pH}$ and contact time to study the effect of temperature on the adsorption. The adsorption isotherm experiments were conducted by adjusting the initial concentrations of copper ions in the range of 10-400 $\mathrm{mg} / \mathrm{L}$. The effects of $\mathrm{pH}$ on the adsorption capacity of amine functionalized Kaolin for copper ions were evaluated in the $\mathrm{pH}$ range of 2-12. The solution $\mathrm{pH}$ was adjusted to certain $\mathrm{pH}$ values by adding $0.1 \mathrm{M} \mathrm{HCl}$ and $0.1 \mathrm{M} \mathrm{NaOH}$ solution.

The amount of copper ions adsorbed by amine functionalized Kaolin was calculated using following mass balance equation:

$$
Q_{\mathrm{e}}=\frac{C_{0}-C_{e}}{m} \times V
$$

Where $Q_{e}(\mathrm{mg} / \mathrm{g})$ is the amount of heavy metal ions adsorbed per gram dry weight of the adsorbent at adsorption equilibrium

time, $C_{0}(\mathrm{mg} / \mathrm{L})$ is the initial concentrations of copper ions and $C_{e}(\mathrm{mg} / \mathrm{L})$ is the equilibrium concentrations of copper ions, $m$ (g) 
is the mass of adsorbent in the adsorption medium and $V(\mathrm{~L})$ is the volume of adsorption medium.

$$
Q_{t}=\frac{C_{0}-C_{t}}{m} \times V
$$

Where $Q_{t}(\mathrm{mg} / \mathrm{g})$ is the amount of adsorbed heavy metal ions adsorbed per gram dry weight of the adsorbent at the time $t(\mathrm{~min})$, $C_{0}(\mathrm{mg} / \mathrm{L})$ is the initial heavy metal ion concentration and $C_{t}(\mathrm{mg} / \mathrm{L})$ is the heavy metal ion concentration at time $t(\mathrm{~min}), m(\mathrm{~g})$ is the mass of adsorbent in the adsorption medium and $V(\mathrm{~L})$ is the volume of adsorption medium.

\section{Results and discussion}

\subsection{Characterizations of Kaolin and functionalized Kaolin}

The particle size and morphological characteristics of Kaolin, Kaolin-PDA and Kaolin-PDA-PEI were obtained by TEM (shown in Fig. 1). It is clear to see that raw Kaolin (Fig. 1A) consists of large particles and compact clearance with plate like structure. The size of these particles is rather unhemogenerous with size about several hundred nanometers. On the other hand, these small particles are piled up into larger aggregates with size about several micrometers. After Kaolin particles were coated with PDA, their structure has not been obviously changed (Fig. 1B). While the color of Kaolin samples was tuned from light grey to khaki grey (insets of Fig. 1A and Fig. 1B). Further immobilization of PEI onto Kaolin-PDA, the color of Kaolin-PDA-PEI was changed to tawny (Inset of Fig. 1C and Fig. 1D). Moreover, we can see that the structure of Kaolin-PDA-PEI has no difference with raw Kaolin, but a thin layer of polymer is covered on the surface of the Kaolin particles (Fig. 1C and Fig. 1D). Based on the above results, we can preliminarily speculate that Kaolin is modified by PDA and PEI through self polymerization of dopamine and subsequently Michael addition reaction. 

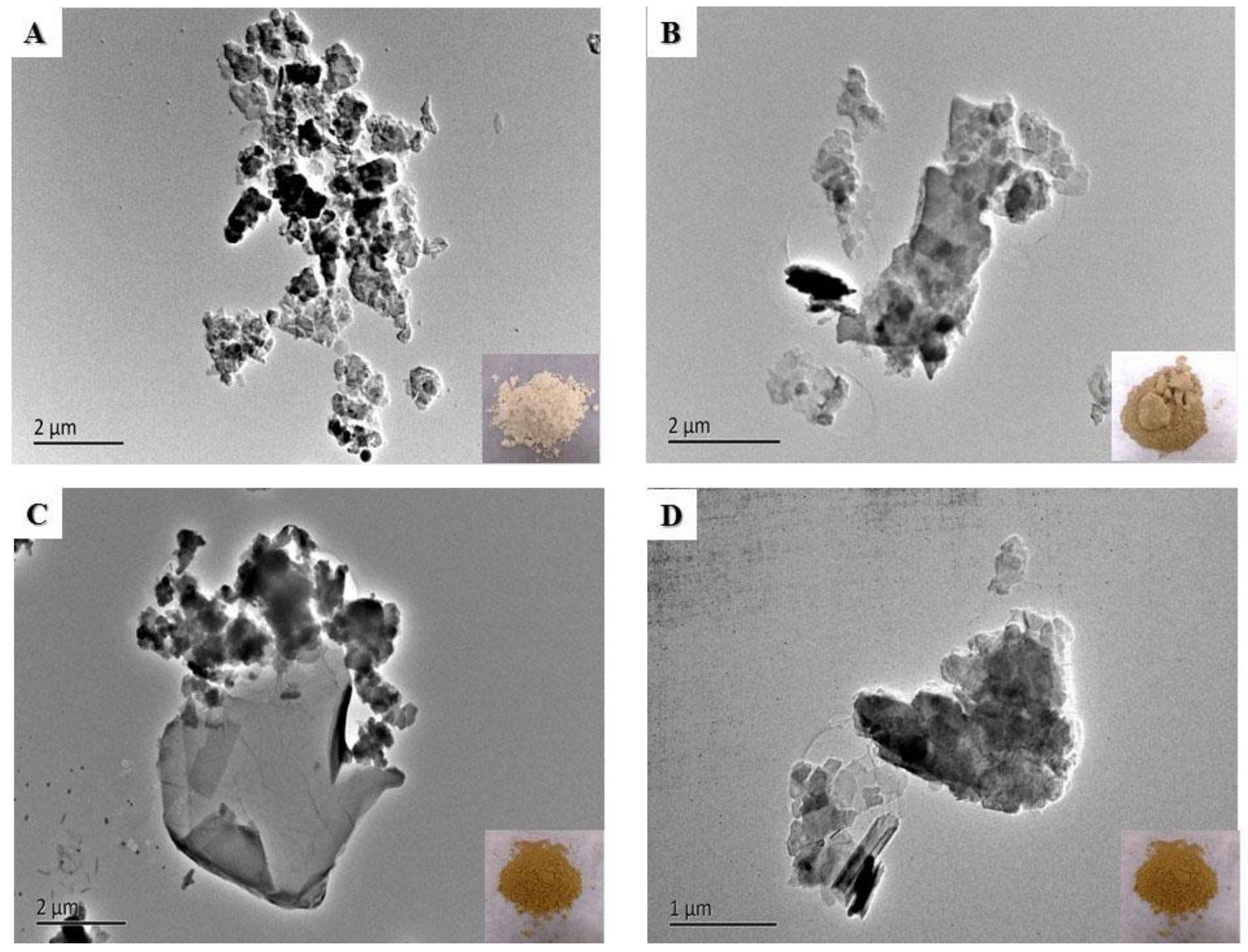

Fig. 1 TEM images of Kaolin (A), Kaolin-PDA (B) and Kaolin-PDA-PEI (C and D). Scale bar $=2 \mu \mathrm{m}(\mathrm{A}-\mathrm{C})$ and scale bar $=1 \mu \mathrm{m}$ (D). The color change of Kaolin samples implied that PDA and PEI have immobilized on Kaolin through mussel inspired chemistry and Michael addition reaction.

The FT-IR spectra of raw Kaolin and modified Kaolin are shown in Fig. 2A. From the FT-IR spectrum of Kaolin, the band assignments are: the peaks at 3695.9 and $3622.3 \mathrm{~cm}^{-1}$ can be assigned to external hydroxyl and internal hydroxyl of Kaolin respectively. Si-O in-plane vibration at $1008.9 \mathrm{~cm}^{-1}$; Al-OH vibration at $914.3 \mathrm{~cm}^{-1}$ and Si-O-Al bending vibration at $538.5 \mathrm{~cm}^{-1}$ were also observed. After surface modified with PDA and PEI, new peak appears at $2974.7 \mathrm{~cm}^{-1}$ was found in Kaolin-PDA-PEI. It can be attributed to stretching vibration of $-\mathrm{CH}_{2}$. Furthermore, new peaks at $1644.3 \mathrm{~cm}^{-1}$ and $1595.1 \mathrm{~cm}^{-1}$ can be ascribed to $-\mathrm{NH}_{2}$ deformation vibration and stretching vibration of aromatic rings of PDA and PEI. The comparison implied that the PEI and PDA have successfully immobilized onto raw Kaolin through facile mussel inspired strategy. 

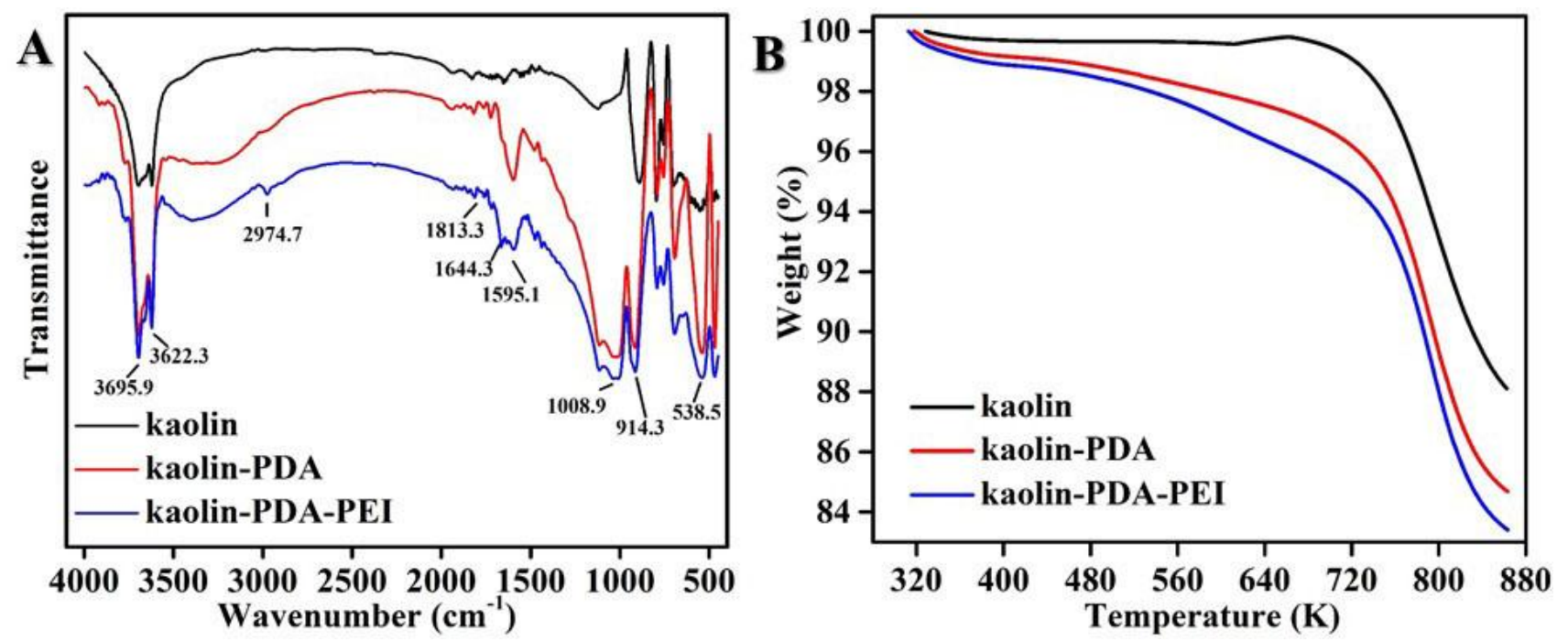

Fig. 2 (A) FT-IR spectra of Kaolin, Kaolin-PDA and Kaolin-PDA-PEI; (B) TGA curves of Kaolin, Kaolin-PDA and Kaolin-PDA-PEI.

TGA is used to study the thermo-stability of raw Kaolin, Kaolin-PDA, and Kaolin-PDA-PEI and to estimate the amount of PEI on the surface of Kaolin. As shown in Fig. 2B, the decomposition temperature of Kaolin is around $670 \mathrm{~K}$. When the temperature was increased to $870 \mathrm{~K}$, the weight loss percentage was reached to about $11.89 \%$. After being modified, the decomposition temperature was decreased. For example the T5 values for kaolin, kaolin modified PDA, and kaolin PDA-PEI are 780,745 , and $720 \mathrm{~K}$, respectively. The weight loss of modified Kaolin below $750 \mathrm{~K}$ is estimated at about $4 \%$ and $7 \%$ corresponding to the decomposition of PDA and PEI, respectively. There is a significant weight loss from 750 to $880 \mathrm{~K}$, which is ascribed to the decomposition of Kaolin. From the change of weight percentage in the TGA curves, it can be calculated that the amount of PDA and PEI is about $4.38 \%$ and $3.57 \%$, respectively, which indicates that the properties of modified Kaolin are preserved. The TGA results clearly showed that the organic films have been introduced on Kaolin through self polymerization of dopamine and further Michael addition reaction between Kaolin-PDA and PEI. 

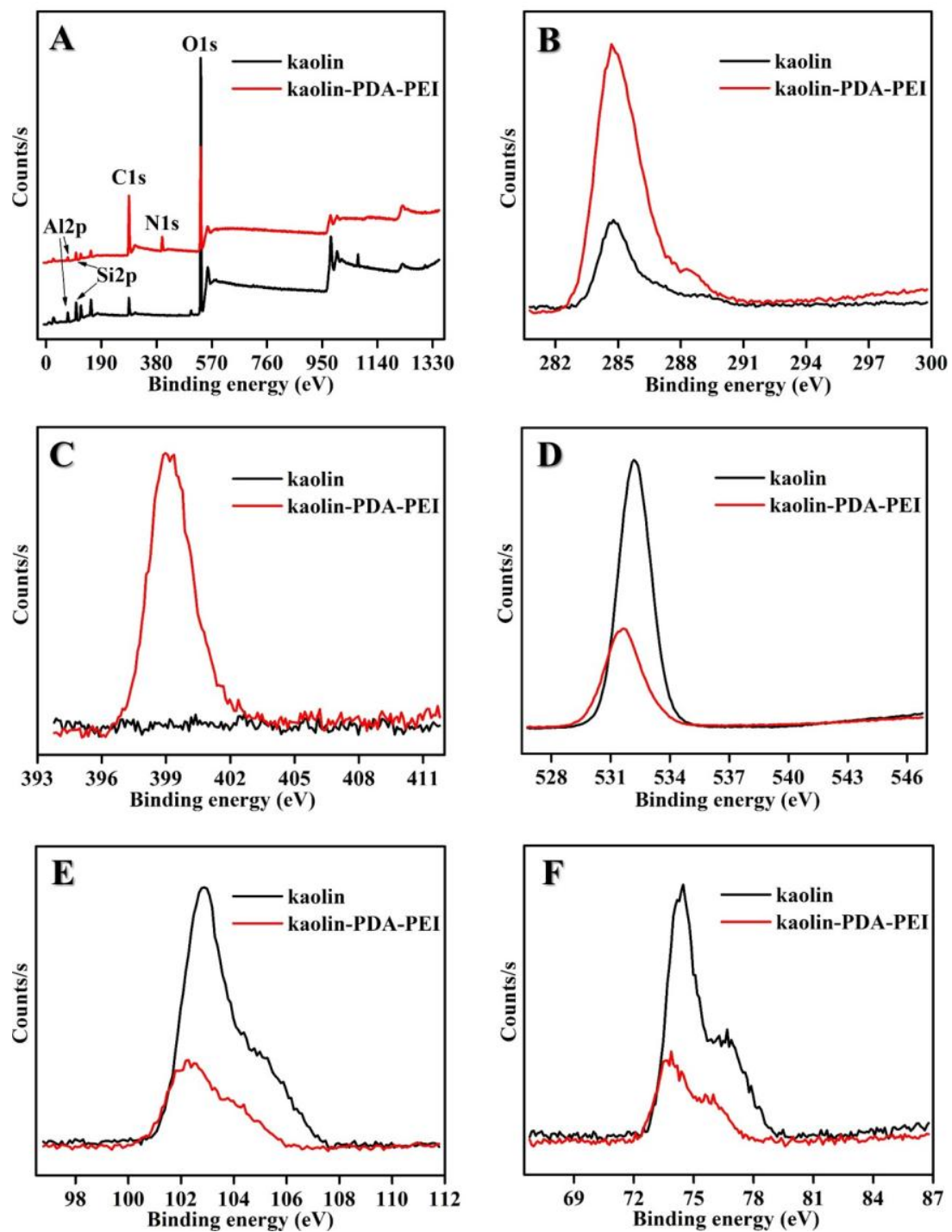

Fig. 3 XPS spectra for Kaolin and Kaolin-PDA-PEI. (A): survey XPS scans from 0 to $1200 \mathrm{eV;} \mathrm{(B-F):} \mathrm{high} \mathrm{resolution} \mathrm{XPS} \mathrm{scans}$ of C1s, N1s, O1s, Si2p, A12p.

The chemical compositions of raw Kaolin and Kaolin-PDA-PEI are investigated by X-ray photoelectron spectroscopy (XPS). From Fig. 3, it can be seen that the elements including $\mathrm{C}, \mathrm{N}, \mathrm{O}, \mathrm{Si}$ and $\mathrm{Al}$ are present in the samples of Kaolin and Kaolin-PDA-PEI (Fig. 3A), and the binding energy peaks of C1s, N1s, O1s, Si2p and Al2p of Kaolin are located at 284.8, 402.51, 532.21, 102.86 and $74.37 \mathrm{eV}$, respectively. After being modified, there are a bit of changes in the location of those elements binding energy peaks. For instance, the peaks of binding energy of $\mathrm{C} 1 \mathrm{~s}, \mathrm{~N} 1 \mathrm{~s}, \mathrm{O} 1 \mathrm{~s}, \mathrm{Si} 2 \mathrm{p}$ and Al2p of Kaolin-PDA-PEI are relocated at $284.84,399.12,531.59,102.37$ and $73.84 \mathrm{eV}$, respectively. According to Fig. 3B-F, it is clear to see that the percentage of $\mathrm{C}$ is increased from $11.8 \%$ to $49.54 \%$. More importantly, there is a significant change in the N percentage, which was increased from $0.44 \%$ to $7.11 \%$. Meanwhile, the percentages of $\mathrm{O}, \mathrm{Si}$ and $\mathrm{Al}$ are decreased from $60.78 \%, 14.0 \%$, and $12.98 \%$ to $31.49 \%, 6.23 \%$ and $5.63 \%$, respectively. These results further confirmed that PEI was incorporated into Kaolin-PDA-PEI. Based on the XPS results in Table 1, the weight percentage of Kaolin to PDA and PEI can be calculated. We found that the weight percentage of Kaolin is $44.5 \%$ and the weight percentage of PDA and PEI is about 55.5\%. The results 
implied that PDA and PEI could effectively coated on Kaolin.

Table 1 Element contents (\%) of Kaolin nanoparticles based on XPS analysis

\begin{tabular}{|c|c|c|c|c|c|}
\hline \multirow{2}{*}{ Sample } & \multicolumn{5}{|c|}{ Atom percentage $(\%)$} \\
\hline & C1s & N1s & O1s & $\mathrm{Si2p}$ & Al2p \\
\hline Kaolin & 11.80 & 0.44 & 60.78 & 14.00 & 12.98 \\
\hline Kaolin-PDA-PEI & 49.54 & 7.11 & 31.49 & 6.23 & 5.63 \\
\hline
\end{tabular}

\subsection{Adsorption experiment studies}

\subsubsection{The effect of contact time and adsorption kinetics}

The adsorption equilibration time is a significance parameter in the adsorption process. Fig. $\mathbf{4 A}$ shows the effect of contact time on the adsorption of copper ions by Kaolin and Kaolin-PDA-PEI. It can be seen that the rapid adsorption of Kaolin-PDA-PEI to copper ions in solution takes place within 20 min, while the adsorption equilibration time of raw Kaolin to copper ions in solution require more than $60 \mathrm{~min}$. The maximum adsorbed copper ions amount at adsorption equilibration time of Kaolin-PDA-PEI is about $20.54 \mathrm{mg} / \mathrm{g}$, which is higher than the maximum amount of adsorbed copper ions by raw Kaolin (about $13.01 \mathrm{mg} / \mathrm{g})$. These results indicate that the amine groups modified Kaolin is in favor of the adsorption to copper ions in solution.

The adsorption kinetics is one of the essential parameters to describe the copper ions uptake rate and control the residue time of the adsorbent at the solid-solution interface, from which the efficiency of the copper ions adsorption by Kaolin-PDA-PEI can be determined [55]. In order to predict the favor adsorption kinetic model, the pseudo-first-order, pseudo-second-order and intraparticle diffusion models are used to fit the experiment data in this study (Fig. 4B).
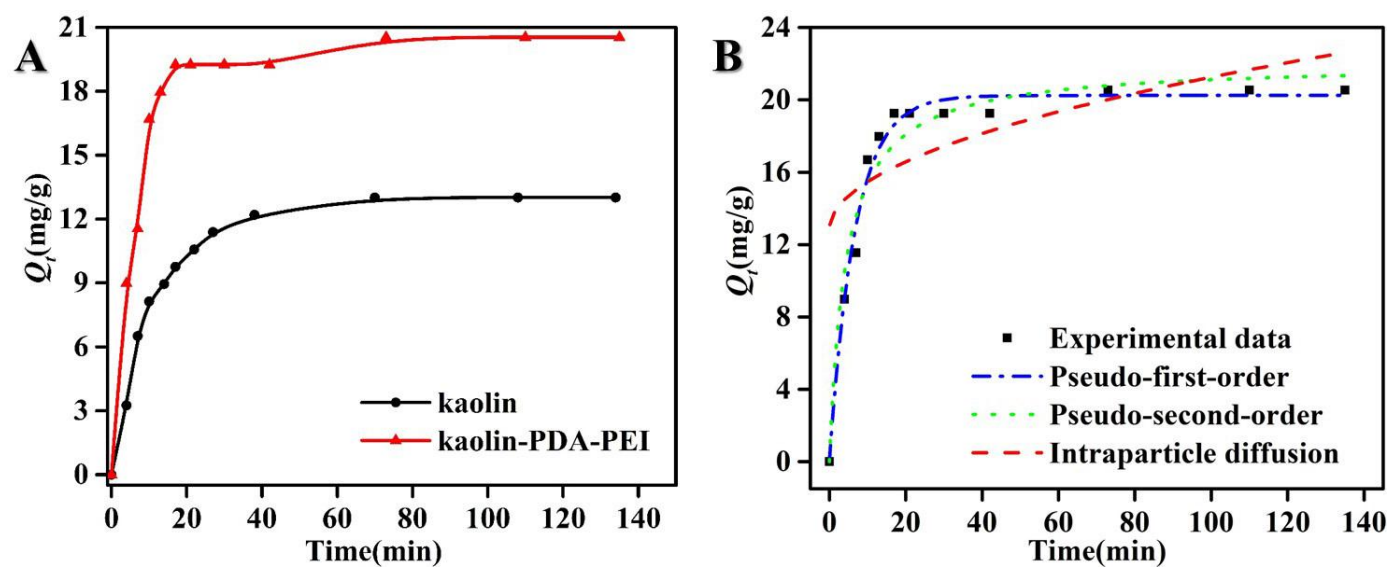

Fig. 4 (A) The adsorption amount of Kaolin-PDA-PEI to $10 \mathrm{mg} / \mathrm{L}$ copper ions at room temperature, initial $\mathrm{pH} 7.1$, and adsorbent dose $10 \mathrm{mg}$. (B) The experiment data are fitted by pseudo-first-order, pseudo-second-order and intraparticle diffusion models. 
The non-linear form of the pseudo-first-order kinetic model can be expressed as follows:

$$
Q_{t}=Q_{e}\left(1-e^{-k_{1} t}\right)
$$

Where $Q_{e}(\mathrm{mg} / \mathrm{g})$ and $Q_{t}(\mathrm{mg} / \mathrm{g})$ are the amount of adsorbed copper ions on the surface of Kaolin-PDA-PEI at equilibrium and at time $t(\mathrm{~min})$, respectively. $k_{l}\left(\mathrm{~min}^{-1}\right)$ is the rate constant of the pseudo-first-order equation, the values of those parameters are listed in Table 2. It is clear to see that the calculated value of $Q_{e}$ from this model is about $20.25 \mathrm{mg} / \mathrm{g}$, which is very close to the value $(20.54 \mathrm{mg} / \mathrm{g})$ of $Q_{e}$ from the adsorption experiment. The value of correlation coefficient $\left(R^{2}\right)$ of this equation is 0.9848 and the value of rate constant $k_{l}$ is about $0.1486 \mathrm{~min}^{-1}$.

The pseudo-second-order kinetic model which is based on the assumption that chemisorption is the rate determining step can be described by follow equation [56]:

$$
\begin{aligned}
& Q_{t}=\frac{k_{2} Q_{e}^{2} t}{1+k_{2} Q_{e} t} \\
& h=k_{2} Q_{e}^{2}
\end{aligned}
$$

Where $k_{2}\left(\mathrm{~g} \mathrm{mg}^{-1} \mathrm{~min}^{-1}\right)$ is the pseudo-second-order rate constant, and $Q_{e}(\mathrm{mg} / \mathrm{g})$ and $Q_{t}(\mathrm{mg} / \mathrm{g})$ are the amount of adsorbed copper ions on the surface of Kaolin-PDA-PEI at equilibrium and at time $t(\mathrm{~min})$, respectively, $h(\mathrm{mg} / \mathrm{g}$ min) represents the initial adsorption rate. According to the Table 2, the value of parameter $h$ is about $5.053 \mathrm{mg} / \mathrm{g}$ min and pseudo-second-order rate constant $k_{2}\left(\mathrm{~g} \mathrm{mg}^{-1} \mathrm{~min}^{-1}\right)$ is 0.01041 . The $Q_{e}$ value of Kaolin-PDA-PEI obtained from the pseudo-second-order equation is about $22.03 \mathrm{mg} / \mathrm{g}$, which also correspond with the experiment data but does not fit well. The lower correlation coefficient $\left(R^{2}=0.9591\right)$ of pseudo-second-order at the side of the pseudo-first-order correlation coefficient also suggest that experimental kinetic data for Kaolin-PDA-PEI to copper ions in solution follow the pseudo-first-order better more than the pseudo-second-order rate model.

The intra-particle diffusion equation is given as:

$$
Q_{t}=k_{p} t^{0.5}+C
$$

Where $k_{p}\left(\mathrm{mg} \mathrm{g}^{-1} \min ^{-1 / 2}\right)$, the intra-particle diffusion rate constant, is listed in Table 2. The value of $k_{p}$ and constant $C$ are 0.8554 and 12.80, respectively. The plot of $Q_{t}$ vs. $t^{0.5}$ using the initial experiment kinetic data up to 140 min gives correlation coefficient value of 0.4462 for the adsorption process. The very low $R^{2}$ value indicates that this adsorption process is not suitable for intra-particle diffusion.

According to those results mentioned above, this adsorption process better fits to the pseudo-first-order model compared to pseudo-second-order kinetic order, the chemisorption plays a significant role in this adsorption process; and the values of correlation coefficient from pseudo-first-order and pseudo-second-order both are over 0.9, which indicates that the chemisorption is accompanied by physisorption in the adsorption process of Kaolin-PDA-PEI to copper ions in solution. 
Table 2 Data of Pseudo-first-order, Pseudo-second-order and Intraparticle diffusion models parameters at 292 K

\begin{tabular}{|c|c|c|}
\hline \multirow[t]{2}{*}{ Models } & \multirow[t]{2}{*}{ Parameters } & Initial concentration $(\mathrm{mg} / \mathrm{L})$ \\
\hline & & 10 \\
\hline \multirow[t]{3}{*}{ Pseudo-first-order equation } & $Q_{e(c a l)}(\mathrm{mg} / \mathrm{g})$ & 20.25 \\
\hline & $k_{l}\left(\min ^{-1}\right)$ & 0.1486 \\
\hline & $R^{2}$ & 0.9848 \\
\hline \multirow[t]{4}{*}{ Pseudo-second-order equation } & $Q_{e(c a l)}(\mathrm{mg} / \mathrm{g})$ & 22.03 \\
\hline & $k_{2}\left(\mathrm{~g} \mathrm{mg}^{-1} \min ^{-1}\right)$ & 0.01041 \\
\hline & $h\left(\mathrm{mg} \mathrm{g}^{-1} \min ^{-1}\right)$ & 5.053 \\
\hline & $R^{2}$ & 0.9591 \\
\hline \multirow[t]{3}{*}{ Intraparticle diffusion } & $k_{p}\left(\mathrm{mg} \mathrm{g}^{-1} \min ^{-0.5}\right)$ & 0.8454 \\
\hline & $C$ & 12.80 \\
\hline & $R^{2}$ & 0.4462 \\
\hline
\end{tabular}

\subsubsection{Adsorption isotherms}

In this study, adsorption isotherm is used to describe the adsorption equilibrium of copper ions at the surface of Kaolin-PDA-PEI, the adsorption equilibrium models could provide some useful information about the adsorption mechanism, the surface properties and the affinity of adsorbent [57]. In order to understand the adsorption mechanism, the experiment data is simulated by Langmuir and Freundlich isotherms models (Fig. 5).

The Langmuir isotherm model is based on the assumption that the adsorption process occurs in a monolayer, homogeneous and finite mode on the absorbent, and there is no interaction between the adsorbed molecules. The Langmuir isotherm mode is represented by following non-linear equation:

$$
Q_{e}=\frac{K_{L} Q_{m} C_{e}}{1+K_{L} C_{e}}
$$

Where $C_{e}(\mathrm{mg} / \mathrm{L})$ is the equilibrium concentration of copper ions, $Q_{e}(\mathrm{mg} / \mathrm{g})$ is the amount of adsorbed copper ions by Kaolin-PDA-PEI at equilibrium time, $Q_{m}(\mathrm{mg} / \mathrm{g})$ is related to the maximum adsorption capacity of the absorbent and $K_{L}(\mathrm{~L} / \mathrm{mg})$ is the Langmuir adsorption constant related to the energy of adsorption. The value of $Q_{m}(\mathrm{mg} / \mathrm{g})$ and $K_{L}(\mathrm{~L} / \mathrm{mg})$ are calculated from the equation of Langmuir isotherm model and shown in Table 3. In this paper, the calculated maximum value of $Q_{m}$ (mg/g) is 60.99 and the $K_{L}(\mathrm{~L} / \mathrm{mg})$ is 0.06354 . The essential characteristics of Langmuir isotherm could be described as a dimensionless equilibrium parameter $\left(R_{L}\right)$ and is defined as followed equation: 


$$
R_{L}=\frac{1}{1+K_{L} C_{0}}
$$

Where $C_{0}(\mathrm{mg} / \mathrm{L})$ is the initial concentration of copper ions and $K_{L}(\mathrm{~L} / \mathrm{mg})$ is the Langmuir constant. The value of $R_{L}$ indicates that the type of isotherm is irreversible when $R_{L}=0$, while the isotherm type is favorable as $0<R_{L}<1$, the isotherm type is linear as $R_{L}=1$ and unfavorable as $R_{L}>1$, the data of $R_{L}$ is shown in Table 3 .

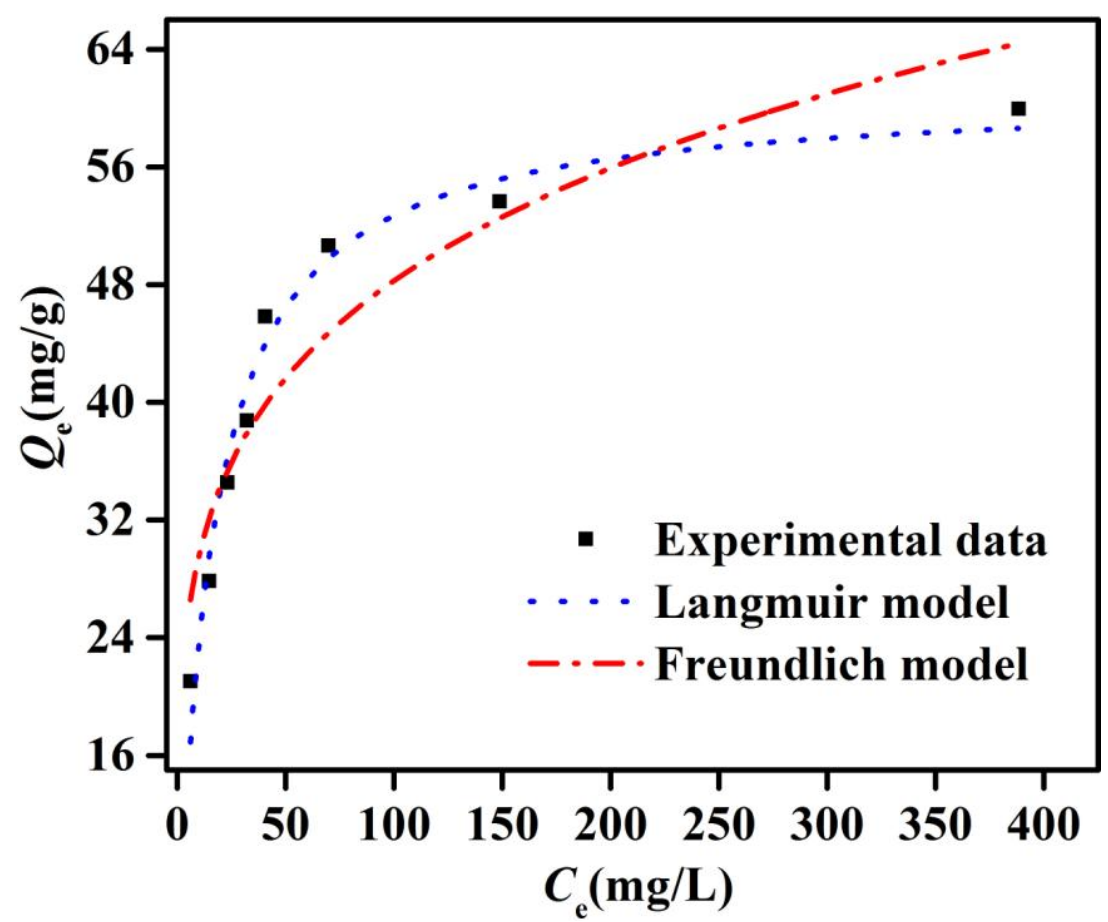

Fig. 5 The adsorption isotherms of $\mathrm{Cu}^{2+}$ ions by Kaolin-PDA-PEI at initial heavy metal ions concentration from 10 to $400 \mathrm{mg} / \mathrm{L}$, absorbent dose 10mg, and room temperature for $60 \mathrm{~min}$, the data from the experiment have been fitted by Langmuir and Freundlich models.

The Freundlich adsorption isotherm equation is applied to monolayer adsorption as well as heterogeneous adsorption and describes the adsorption mechanism on the heterogeneous surface in low concentration system. The non-linear form of Freundlich isotherm model can be represented as following:

$$
Q_{e}=K_{F} C_{e}^{\frac{1}{n}}
$$

Where $Q_{e}(\mathrm{mg} / \mathrm{g})$ is the amount of adsorbed copper ions per unit mass of Kaolin-PDA-PEI at equilibrium, $C_{e}(\mathrm{mg} / \mathrm{L})$ is the equilibrium concentration of copper ions. And $K_{F}\left[(\mathrm{mg} / \mathrm{g})(\mathrm{L} / \mathrm{mg})^{1 / \mathrm{n}}\right]$ is the adsorption equilibrium constant of Freundlich isotherm model, represents the adsorption capacity of Kaolin-PDA-PEI. $n$ is the Freundlich constant and represents the degree of dependence of adsorption on the equilibrium concentration. Generally speaking, the value of $n^{-1}$ in the range of $0-1$ illustrates that the adsorption process is favorable; while the value of $n^{-1}$ in the range of $0.1-0.5$ represent that adsorbate is much favorably adsorbed on adsorbent. On the contrary, while the value of $n^{-1}$ is beyond 2. It means that the adsorbates are unfavorably adsorbed by adsorbents. The values of $K_{F}$ and $n$ are calculated from the equation of the Freundlich isotherm model and listed in Table 3. It 
can be observed that the value of $K_{F}$ and $n$ are $18.13(\mathrm{mg} / \mathrm{g})(\mathrm{L} / \mathrm{mg})^{1 / \mathrm{n}}$ and 4.704, respectively.

As seen from the Fig. 5, the equilibrium uptake increased with the increasing of equilibrium copper ions concentration at the range of experimental concentration. This is a result of the increase in the driving force from the concentration gradient [58], the active sites of Kaolin-PDA-PEI are surrounded by much more copper ions as the copper ion concentration increased. The more copper ions are adsorbed. Thus the value of $Q_{e}(\mathrm{mg} / \mathrm{g})$ increased with the increasing of equilibrium copper ion concentrations. From the Table 3, it is clear to see that the experimental data are better fitted by Langmuir isotherm model $\left(R^{2}=0.9672\right)$ than Freundlich isotherm model $\left(R^{2}=0.8668\right)$. The above results indicate that chemisorption plays an essential role in the adsorption process. Furthermore, the value of $R_{L}$ is found to be 0.6114 . This confirms that Kaolin-PDA-PEI is favorable for adsorption of copper ions in solution under the conditions used in this study. The calculated value of $n^{-1}$ is 0.2126 , indicating that copper ions is very favorably adsorbed by the Kaolin-PDA-PEI. This also suggests the formation of a heterogeneous surface.

Table 3 Data of adsorption isotherms of Langmuir and Freundlich models for the adsorption on Kaolin-PDA-PEI at 303 K.

\begin{tabular}{llc}
\hline Isotherms & Parameters & Temperature $(\mathrm{K})$ \\
\cline { 2 - 3 } & & 303 \\
\hline Langmuir & $Q_{m}(\mathrm{mg} / \mathrm{g})$ & 60.99 \\
& $K_{L}(\mathrm{~L} / \mathrm{mg})$ & 0.06354 \\
& $R_{L}$ & $0.03786-0.6114$ \\
& $R^{2}$ & 0.9672 \\
$K_{F}\left[(\mathrm{mg} / \mathrm{g})(\mathrm{L} / \mathrm{mg})^{1 / \mathrm{n}}\right]$ & 18.13 \\
& $n$ & 4.704 \\
\hline
\end{tabular}

\subsubsection{The effect of solution $\mathrm{pH}$ on copper ions uptake}

The solution $\mathrm{pH}$ plays a significant role in the adsorption process of adsorbates onto adsorbents [59]. In order to study the effect of solution $\mathrm{pH}$ on the surface of Kaolin-PDA-PEI, the batch experiment is carried out at different solution $\mathrm{pH}$ range from 2 to 12 at room temperature at a fixed copper ion concentration of $10 \mathrm{mg} / \mathrm{L}$. Fig. 6 shows the variations in the removal of copper ions at various solution initial $\mathrm{pH}$. It is evident that the maximum removal of copper ions is observed at $\mathrm{pH}$ of 11.1 . With the increasing of $\mathrm{pH}$ from 2 to 12 , the amount of adsorbed copper ions increases from 1.8 to $45.1 \mathrm{mg} / \mathrm{g}$ at initial $\mathrm{pH}$ of 11.1 , and then decreases to $40.9 \mathrm{mg} / \mathrm{g}$ with further increase $\mathrm{pH}$ values. This may be the result of competitive adsorption effect and the protonation of amine groups. A high concentration of $\mathrm{H}^{+}$at acidic $\mathrm{pH}$ leads to the protonation of amine groups. Therefore, copper ions are difficult to be adsorbed by active sites on the surface of Kaolin-PDA-PEI. The increase in $\mathrm{pH}$ from initial $\mathrm{pH} 2$ to 11.1 during adsorption 
indicates the decrease in hydrogen ions concentration in the solution [60] and increase of copper ion removal efficiency. The significant change of adsorption capacity of Kaolin-PDA-PEI is observed at $\mathrm{pH} 6$ to 8 . The reason may be the effect of formation of copper hydroxide precipitation. No significant change of adsorption capacity of Kaolin-PDA-PEI at pH 9.9 to 11.1 was found. The decrease of amount of adsorbed copper ions at $\mathrm{pH} 12$ suggests that protonation of amine groups is not effective in low concentration of free hydrogen ions solution. In a word, the increase of solution $\mathrm{pH}$ is beneficial to the adsorption of copper ions on the surface of Kaolin-PDA-PEI.

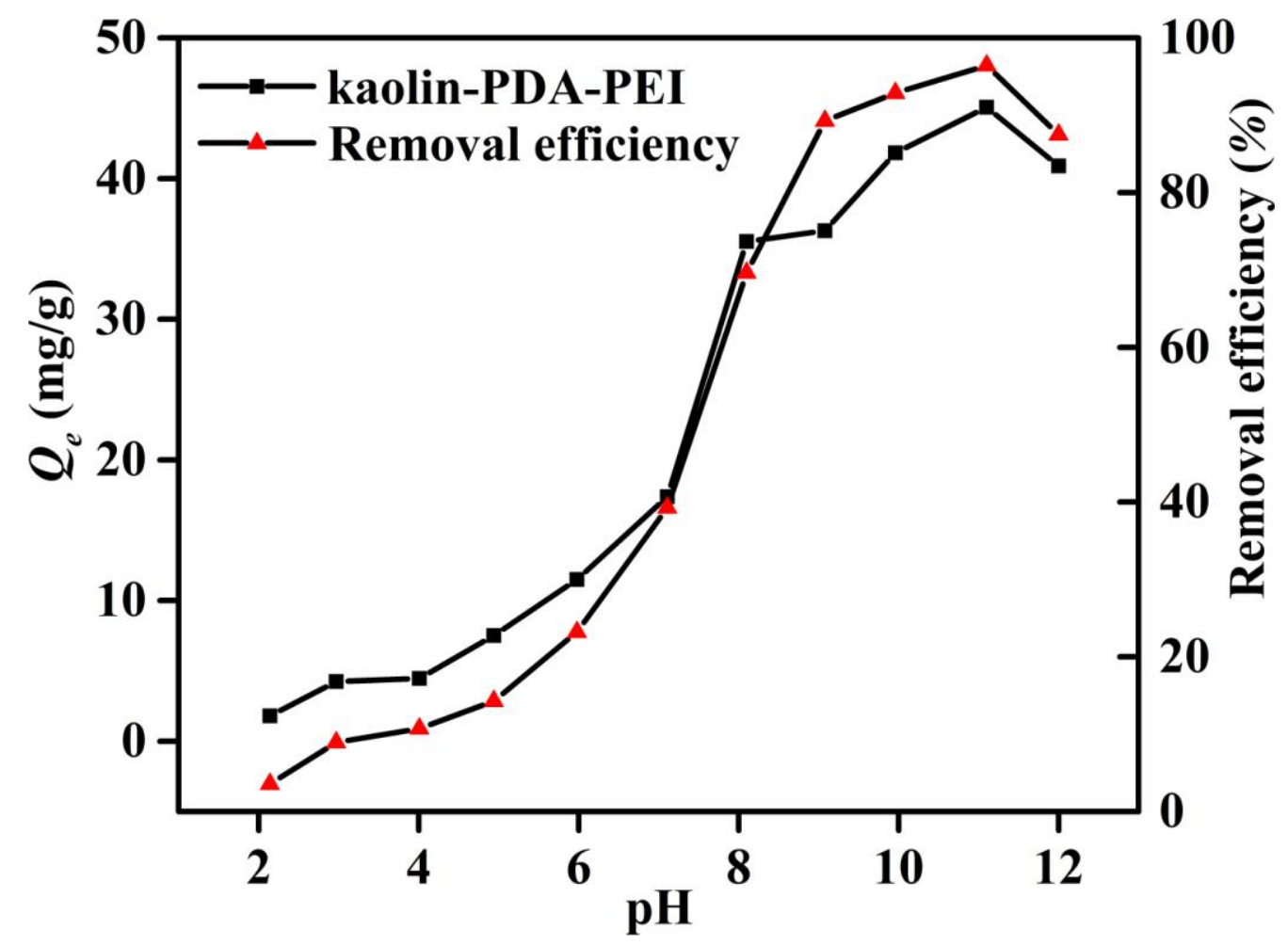

Fig. 6 The effect of initial $\mathrm{pH}$ of copper ions solution on adsorption of the $\mathrm{Cu}^{2+}$ onto Kaolin-PDA-PEI. Experimental condition: 10 $\mathrm{mg} / \mathrm{L}, \mathrm{T}=$ room temperature.

\subsubsection{The effect of temperature and adsorption thermodynamics}

Temperature is one of most important factor for adsorption process of Kaolin-PDA-PEI. In order to study the effect of temperature, the batch experiment is carried out for the initial concentration of copper ions at $10 \mathrm{mg} / \mathrm{L}$ and five different temperatures, i.e., 293.15, 303.15 313.15, 323.15 and 333.15 K, at pH 7.1. Fig. 7A shows the amount of copper ions adsorbed by Kaolin-PDA-PEI at equilibrium time at different temperature. It can be seen that the amount of copper ions adsorbed by Kaolin-PDA-PEI was increased from 18.1 to $30.9 \mathrm{mg} / \mathrm{g}$ with the increase of temperature from 293 to $333 \mathrm{~K}$, suggesting that the adsorption reaction is an endothermic process. The reason may be that the physical bonding between copper ions and the active sites of Kaolin-PDA-PEI weakened and the move ability of adsorbent increased as the temperature increased. Thus the value of $Q_{e}$ $(\mathrm{mg} / \mathrm{g})$ increased with the increasing of temperature.

In order to estimate the effect of temperature on the adsorption of copper ions onto Kaolin-PDA-PEI, the three basic 
thermodynamic parameters, entropy $\left(\Delta S^{0}\right)$, enthalpy $\left(\Delta H^{0}\right)$ and Gibbs free energy $\left(\Delta G^{0}\right)$ are calculated from the temperature dependent adsorption data. The standard entropy change, enthalpy change and Gibbs free energy change can be calculated from the following equations:

$$
\begin{aligned}
& \ln K \alpha=\frac{\Delta S^{0}}{R}-\frac{\Delta H^{0}}{R \cdot T} \\
& K \alpha=\frac{Q_{e}}{C_{e}} \\
& \Delta G^{0}=-R T \ln K \alpha
\end{aligned}
$$

Where $K \alpha$ is the adsorption equilibrium constant and the $R$ is the gas constant $(8.314 \mathrm{~J} / \mathrm{mol} \cdot \mathrm{K})$. $T$ is the temperature of the solution $(\mathrm{K}), Q_{e}$ is the amount of adsorbed cooper ions at equilibrium $(\mathrm{mg} / \mathrm{g})$ and the $C_{e}$ is the equilibrium concentration of copper ions. Considering the relation between the Gibbs free energy change $\left(\Delta G^{0}\right)$ and $K \alpha$, the enthalpy change $\left(\Delta H^{0}\right)$ and entropy change $\left(\Delta S^{0}\right)$ are determined from the slope and intercept of the Van't Hoff plots of $\ln K \alpha$ versus of $1 / T(\mathbf{F i g} .7 \mathbf{B})$. The value of $\Delta S^{0}, \Delta G^{0}$, $\Delta H^{0}$, and other thermodynamic parameters at various temperatures are listed in Table $\mathbf{4}$.
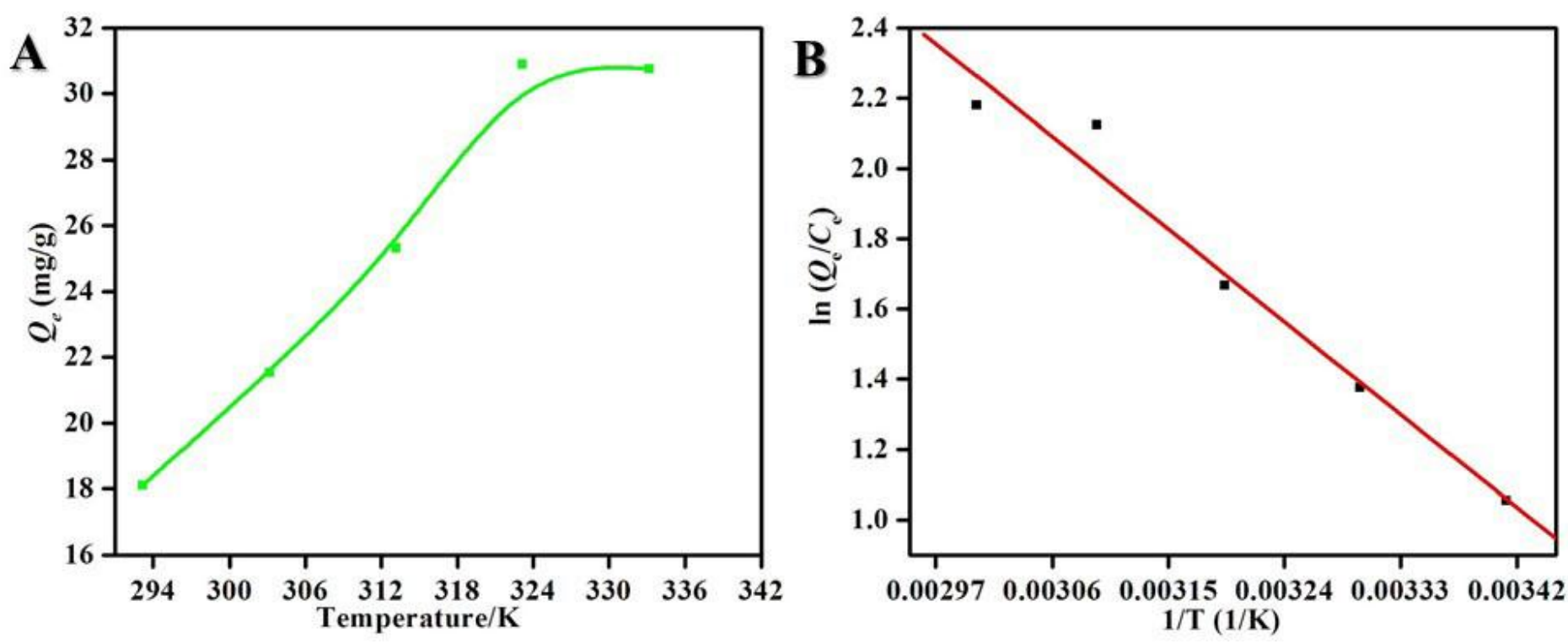

Fig. 7 (A) Effect of temperature on the adsorption of $\mathrm{Cu}^{2+}$ by Kaolin-PDA-PEI. Experimental condition: $\mathrm{C}_{\mathrm{Cu}}^{2+}=10 \mathrm{mg} / \mathrm{L}$, pH $=$ 7.1, $\mathrm{t}=60 \mathrm{~min}$. (B) Van't Hoff plot for the adsorption for the $\mathrm{Cu}^{2+}$ onto Kaolin-PDA-PEI.

According to the result from Table 4, it can be found that the value of Gibbs free energy change in various temperature is negative. The equilibrium constant $K \alpha$,was decreased from -2.573 to $-5.706 \mathrm{~kJ} / \mathrm{mol}$, which indicates that the adsorption reaction is a spontaneous and irreversible process. The decrease of the value of Gibbs free energy change suggests that the adsorption process of copper ions onto Kaolin-PDA-PEI becomes more favorable at higher temperature. The value of entropy change and enthalpy change calculated from the plots of $\ln K \alpha$ versus of $1 / T$ are given as $0.09203 \mathrm{~kJ} / \mathrm{mol} \mathrm{K}$ and $24.39 \mathrm{~kJ} / \mathrm{mol}$, respectively. The positive value of $\Delta H^{0}$ suggests that the adsorption on the surface of Kaolin-PDA-PEI is an endothermic process. The $\Delta S^{0}$ positive value indicates that the randomness increased at the solid-liquid interface during the adsorption process of copper ions on 
Kaolin-PDA-PEI. More importantly, the amount of functional groups (e.g. amine groups) can be adjusted by change the experimental conditions. It can be expected that the adsorption capability of Kaolin-PDA-PEI towards copper ions will increased when the amount of PEI was increased. Furthermore, other surface modification strategies relied on mussel inspired chemistry, which combined with free radical polymerization, single electron transfer living radical polymerization or reversible addition fragmentation chain transfer polymerization can be also developed for preparation of a large number of functionalized adsorbents.[61-64] The properties of these adsorbents can be well designed according to the demand. It is therefore, the mussel inspired strategy described in this work should be a general tool for fabrication of many multifunctional composites for different environmental applications.

Table 4 Data of the thermodynamic parameters for the adsorption of copper ions onto Kaolin-PDA-PEI

\begin{tabular}{cccc}
\hline $\boldsymbol{T}(\mathbf{K})$ & $\boldsymbol{\Delta G ^ { 0 } ( \mathbf { k J } / \mathbf { m o l } )}$ & $\boldsymbol{\Delta H ^ { \boldsymbol { 0 } } ( \mathbf { k J } / \mathbf { m o l } )}$ & $\Delta \boldsymbol{S}^{\boldsymbol{0}}(\mathbf{k J} / \mathbf{m o l ~ K})$ \\
\hline 293.15 & -2.573 & 24.39 & 0.09203 \\
303.15 & -3.470 & & \\
313.15 & -4.340 & \\
323.15 & -5.706 & \\
\hline 333.15 & -6.038 & \\
\hline
\end{tabular}

\section{Conclusions}

The amine functionalized Kaolin is prepared via mussel inspired and Michael addition reaction. A series of characterization analyses including FT-IR, TEM, TGA, and XPS evidence the successful modification of Kaolin with PDA and PEI. The present study confirms the promotion in the capability and effectiveness of Kaolin-PDA-PEI as an environmental adsorbent for the copper ions removal in solution. Adsorption behavior of copper ions onto Kaolin-PDA-PEI was affected by experimental parameters such as solution $\mathrm{pH}$, contact time, temperature and initial concentrations of copper ions. It can be found that the adsorption process of copper ions on Kaolin-PDA-PEI is favored at high solution $\mathrm{pH}$. The experimental data are found to be better fitted by pseudo-first-order and the adsorption isotherms are better described by the Langmuir isotherm model in this study. The thermodynamic experiment indicates that the adsorption of copper ions on Kaolin-PDA-PEI is spontaneous, irreversible and endothermic process. Thus, mussel inspiration strategy described in this work could be a promising method for surface modification and enhancement adsorption capacity of different materials for its universality.

\section{Acknowledgments}

This research was supported by the National Science Foundation of China (Nos. 21201108, 51363016, 21474057, 21564006, 21561022), and the National 973 Project (Nos. 2011CB935700). 


\section{References}

[1] M.A. Tofighy, T. Mohammadi, Adsorption of divalent heavy metal ions from water using carbon nanotube sheets, J. Hazard. Mater., 185 (2011) 140-147.

[2] Y. Meng, D. Chen, Y. Sun, D. Jiao, D. Zeng, Z. Liu, Adsorption of Cu 2+ ions using chitosan-modified magnetic Mn ferrite nanoparticles synthesized by microwave-assisted hydrothermal method, Appl. Surf. Sci., 324 (2015) 745-750.

[3] J. Wang, X. Ma, G. Fang, M. Pan, X. Ye, S. Wang, Preparation of iminodiacetic acid functionalized multi-walled carbon nanotubes and its application as sorbent for separation and preconcentration of heavy metal ions, J. Hazard. Mater., 186 (2011) 1985-1992.

[4] S. Zhang, J. Li, M. Zeng, J. Xu, X. Wang, W. Hu, Polymer nanodots of graphitic carbon nitride as effective fluorescent probes for the detection of Fe 3+ and $\mathrm{Cu} 2+$ ions, Nanoscale, 6 (2014) 4157-4162.

[5] F. Pizarro, M. Olivares, V. Gidi, M. Araya, The gastrointestinal tract and acute effects of copper in drinking water and beverages, Rev Environ health, 14 (1999) 231-238.

[6] M. Kazemipour, M. Ansari, S. Tajrobehkar, M. Majdzadeh, H.R. Kermani, Removal of lead, cadmium, zinc, and copper from industrial wastewater by carbon developed from walnut, hazelnut, almond, pistachio shell, and apricot stone, J Hazard Mater, 150 (2008) 322-327.

[7] P. Luo, Y. Zhao, B. Zhang, J. Liu, Y. Yang, J. Liu, Study on the adsorption of Neutral Red from aqueous solution onto halloysite nanotubes, Water Res., 44 (2010) 1489-1497.

[8] D.C. Culita, C.M. Simonescu, M. Dragne, N. Stanica, C. Munteanu, S. Preda, O. Oprea, Effect of surfactant concentration on textural, morphological and magnetic properties of $\mathrm{CoFe} 2 \mathrm{O} 4$ nanoparticles and evaluation of their adsorptive capacity for $\mathrm{Pb}$ (II) ions, Ceram. Int., (2015) 10.1016/j.ceramint.2015.1007.1150.

[9] M. Imamoglu, O. Tekir, Removal of copper (II) and lead (II) ions from aqueous solutions by adsorption on activated carbon from a new precursor hazelnut husks, Desalination, 228 (2008) 108-113.

[10] M. Kaur, N. Kaur, K. Jeet, P. Kaur, MgFe2O4 nanoparticles loaded on activated charcoal for effective removal of Cr (VI)-A Novel approach, Ceram. Int., (2015) 10.1016/j.ceramint.2015.1008.1040.

[11] S. Larous, A.-H. Meniai, M.B. Lehocine, Experimental study of the removal of copper from aqueous solutions by adsorption using sawdust, Desalination, 185 (2005) 483-490.

[12] A. Papandreou, C. Stournaras, D. Panias, Copper and cadmium adsorption on pellets made from fired coal fly ash, J Hazard Mater, 148 (2007) 538-547.

[13] V. Nikolić, M. Komljenović, N. Marjanović, Z. Baščarević, R. Petrović, Lead immobilization by geopolymers based on mechanically activated fly ash, Ceram. Int., 40 (2014) 8479-8488.

[14] J. Perić, M. Trgo, N.V. Medvidović, Removal of zinc, copper and lead by natural zeolite-a comparison of adsorption isotherms, Water research, 38 (2004) 1893-1899.

[15] K. Chu, Removal of copper from aqueous solution by chitosan in prawn shell: adsorption equilibrium and kinetics, J Hazard Mater, 90 (2002) 77-95.

[16] D. Mohan, C.U. Pittman, P.H. Steele, Single, binary and multi-component adsorption of copper and cadmium from aqueous solutions on Kraft lignin — a biosorbent, J Colloid Interface Sci, 297 (2006) 489-504.

[17] W.W. Ngah, M. Hanafiah, Adsorption of copper on rubber (Hevea brasiliensis) leaf powder: Kinetic, equilibrium and thermodynamic studies, Biochem Eng J, 39 (2008) 521-530.

[18] R. Han, W. Zou, Z. Zhang, J. Shi, J. Yang, Removal of copper (II) and lead (II) from aqueous solution by manganese oxide coated sand: I. Characterization and kinetic study, J Hazard Mater, 137 (2006) 384-395.

[19] Y.P. Kumar, P. King, V. Prasad, Removal of copper from aqueous solution using Ulva fasciata sp.- - a marine green algae, J Hazard Mater, 137 (2006) 367-373.

[20] Y.-H. Li, J. Ding, Z. Luan, Z. Di, Y. Zhu, C. Xu, D. Wu, B. Wei, Competitive adsorption of Pb 2+, Cu 2+ and Cd 2+ ions from aqueous solutions by multiwalled carbon nanotubes, Carbon, 41 (2003) 2787-2792.

[21] Y.-H. Li, Z. Luan, X. Xiao, X. Zhou, C. Xu, D. Wu, B. Wei, Removal of Cu2+ ions from aqueous solutions by carbon nanotubes, Adsorpt Sci Technol, 21 (2003) 475-485.

[22] G. Sheng, J. Li, D. Shao, J. Hu, C. Chen, Y. Chen, X. Wang, Adsorption of copper (II) on multiwalled carbon nanotubes in the 
absence and presence of humic or fulvic acids, J. Hazard. Mater., 178 (2010) 333-340.

[23] S. Yang, J. Li, D. Shao, J. Hu, X. Wang, Adsorption of Ni (II) on oxidized multi-walled carbon nanotubes: effect of contact time, pH, foreign ions and PAA, J. Hazard. Mater., 166 (2009) 109-116.

[24] Y. Xie, Q. Huang, M. Liu, K. Wang, Q. Wan, F. Deng, L. Lu, X. Zhang, Y. Wei, Mussel Inspired Functionalization of Carbon Nanotubes for Heavy Metal Ion Removal, RSC Adv., (2015) 10.1039/C1035RA08908E.

[25] C. Cheng, S. Li, J. Zhao, X. Li, Z. Liu, L. Ma, X. Zhang, S. Sun, C. Zhao, Biomimetic assembly of polydopamine-layer on graphene: Mechanisms, versatile 2D and 3D architectures and pollutant disposal, Chem.Eng. J., 228 (2013) 468-481.

[26] S.-T. Yang, Y. Chang, H. Wang, G. Liu, S. Chen, Y. Wang, Y. Liu, A. Cao, Folding/aggregation of graphene oxide and its application in $\mathrm{Cu}^{2+}$ removal, J. Colloid Interf. Sci., 351 (2010) 122-127.

[27] K.G. Bhattacharyya, S.S. Gupta, Kaolinite, montmorillonite, and their modified derivatives as adsorbents for removal of Cu (II) from aqueous solution, Sep Purif Technol, 50 (2006) 388-397.

[28] K.G. Bhattacharyya, S.S. Gupta, Kaolinite and montmorillonite as adsorbents for Fe (III), Co (II) and Ni (II) in aqueous medium, Appl Clay Sci, 41 (2008) 1-9.

[29] E. Tavani, C. Volzone, Adsorption of chromium(III) from a tanning wastewater on kaolinite, J Soc Leath Tech ch, 81 (1997) 143-148.

[30] F. Hindryckx, P. Dubois, M. Patin, R. Jerome, P. Teyssie, M.G. Marti, Interfacial adhesion in polyethylene-kaolin composites: Improvement by maleic anhydride - grafted polyethylene, J appl polym sci, 56 (1995) 1093-1105.

[31] H. Ming, K.M. Spark, Radio frequency plasma-induced hydrogen bonding on kaolinite, J Phys Chem B, 107 (2003) $694-702$.

[32] Y. Liu, K. Ai, L. Lu, Polydopamine and its Derivative Materials: Synthesis and Promising Applications in Energy, Environmental, and Biomedical fields, Chem. Rev., (2014) DOI: 10.1021/cr400407a.

[33] J.H. Waite, T.J. Housley, M.L. Tanzer, Peptide repeats in a mussel glue protein: theme and variations, Biochemistry, 24 (1985) 5010-5014.

[34] H. Lee, S.M. Dellatore, W.M. Miller, P.B. Messersmith, Mussel-inspired surface chemistry for multifunctional coatings, Science, 318 (2007) 426-430.

[35] H. Lee, N.F. Scherer, P.B. Messersmith, Single-molecule mechanics of mussel adhesion, Proc Nat Acad Sci, 103 (2006) 12999-13003.

[36] B. Fei, B. Qian, Z. Yang, R. Wang, W. Liu, C. Mak, J.H. Xin, Coating carbon nanotubes by spontaneous oxidative polymerization of dopamine, Carbon, 46 (2008) 1795-1797.

[37] S.H. Yang, S.M. Kang, K.-B. Lee, T.D. Chung, H. Lee, I.S. Choi, Mussel-inspired encapsulation and functionalization of individual yeast cells, J Am Chem Soc, 133 (2011) 2795-2797.

[38] Z. Zhao, J. Li, T. Wen, C. Shen, X. Wang, A. Xu, Surface functionalization graphene oxide by polydopamine for high affinity of radionuclides, Colloid Surface A (2015).

[39] X. Zhang, J. Ji, X. Zhang, B. Yang, M. Liu, W. Liu, L. Tao, Y. Chen, Y. Wei, Mussel inspired modification of carbon nanotubes using RAFT derived stimuli-responsive polymers, RSC Adv, 3 (2013) 21817-21823.

[40] X. Zhang, M. Liu, X. Zhang, F. Deng, C. Zhou, J. Hui, W. Liu, Y. Wei, Interaction of tannic acid with carbon nanotubes: enhancement of dispersibility and biocompatibility, Toxicol Res, 4 (2015) 160-168.

[41] X. Zhang, M. Liu, Y. Zhang, B. Yang, Y. Ji, L. Feng, L. Tao, S. Li, Y. Wei, Combining Mussel-inspired Chemistry and the Michael Addition Reaction to Disperse Carbon Nanotubes, RSC Adv., 2 (2012) 12153-12155.

[42] X. Zhang, K. Wang, M. Liu, X. Zhang, L. Tao, Y. Chen, Y. Wei, Polymeric AIE-based nanoprobes for biomedical applications: recent advances and perspectives, Nanoscale, (2015).

[43] Q. Wan, J. Tian, M. Liu, G. Zeng, Q. Huang, K. Wang, Q. Zhang, F. Deng, X. Zhang, Y. Wei, Surface modification of carbon nanotubes via combination of mussel inspired chemistry and chain transfer free radical polymerization, Appl. Surf. Sci., 346 (2015) 335-341.

[44] X. Zhang, Q. Huang, M. Liu, J. Tian, G. Zeng, Z. Li, K. Wang, Q. Zhang, Q. Wan, F. Deng, Preparation of amine functionalized carbon nanotubes via a bioinspired strategy and their application in Cu 2+ removal, Appl. Surf. Sci., 343 (2015) 19-27.

[45] X. Zhang, G. Zeng, J. Tian, Q. Wan, Q. Huang, K. Wang, Q. Zhang, M. Liu, F. Deng, Y. Wei, PEGylation of carbon nanotubes 
via mussel inspired chemistry: Preparation, characterization and biocompatibility evaluation, Appl. Surf. Sci., 351 (2015) 425-432.

[46] Y. Cao, X. Zhang, L. Tao, K. Li, Z. Xue, L. Feng, Y. Wei, Mussel-inspired Chemistry and Michael addition Reaction for Efficient Oil/water Separation, ACS Appl. Mater. Interf., 5 (2013) 4438-4442.

[47] L. Xu, N. Liu, Y. Cao, F. Lu, Y. Chen, X. Zhang, L. Feng, Y. Wei, Mercury Ion Responsive Wettability and Oil Water Separation, ACS Appl. Mater. Interf., 6 (2014) 13324-13329.

[48] J. Tian, H. Zhang, M. Liu, F. Deng, H. Huang, Q. Wan, Z. Li, K. Wang, X. He, X. Zhang, A bioinspired strategy for surface modification of silica nanoparticles, Appl. Surf. Sci., 357 (2015) 1996-2003.

[49] M. Liu, J. Ji, X. Zhang, X. Zhang, B. Yang, F. Deng, Z. Li, K. Wang, Y. Yang, Y. Wei, Self-polymerization of dopamine and polyethyleneimine: novel fluorescent organic nanoprobes for biological imaging applications, J. Mater. Chem. B, 3 (2015) 3476-3482.

[50] X. Zhang, K. Wang, M. Liu, X. Zhang, L. Tao, Y. Chen, Y. Wei, Polymeric AIE-based nanoprobes for biomedical applications: recent advances and perspectives, Nanoscale, 7 (2015) 11486-11508.

[51] X. Zhang, S. Wang, L. Xu, Y. Ji, L. Feng, L. Tao, S. Li, Y. Wei, Biocompatible Polydopamine Fluoresecent Organic Nanoparticles: Facile Preparation and Cell Imaging, Nanoscale, 4 (2012) 5581-5584.

[52] V. Ball, D. Del Frari, V. Toniazzo, D. Ruch, Kinetics of polydopamine film deposition as a function of pH and dopamine concentration: Insights in the polydopamine deposition mechanism, J. Colloid Interf. Sci., 386 (2012) 366-372.

[53] D.R. Dreyer, D.J. Miller, B.D. Freeman, D.R. Paul, C.W. Bielawski, Perspectives on poly (dopamine), Chem. Sci., 4 (2013) 3796-3802.

[54] X. Zhang, Q. Huang, M. Liu, J. Tian, G. Zeng, Z. Li, K. Wang, Q. Zhang, Q. Wan, F. Deng, Preparation of amine functionalized carbon nanotubes via a bioinspired strategy and their application in Cu 2+ removal, Appl Clay Sci, 343 (2015) $19-27$.

[55] E. Demirbas, M. Kobya, E. Senturk, T. Ozkan, Adsorption kinetics for the removal of chromium (VI) from aqueous solutions on the activated carbons prepared from agricultural wastes, Water Sa, 30 (2004) p. 533-539.

[56] I.A. Darwish, D.A. Blake, Development and validation of a one-step immunoassay for determination of cadmium in human serum, Anal Chem, 74 (2002) 52-58.

[57] M. Brdar, M. Šćiban, A. Takači, T. Došenović, Comparison of two and three parameters adsorption isotherm for Cr (VI) onto Kraft lignin, Chem Eng J, 183 (2012) 108-111.

[58] Y. Yao, H. Bing, X. Feifei, C. Xiaofeng, Equilibrium and kinetic studies of methyl orange adsorption on multiwalled carbon nanotubes, Chem Eng J, 170 (2011) 82-89.

[59] W. Konicki, I. Pełech, E. Mijowska, I. Jasińska, Adsorption of anionic dye Direct Red 23 onto magnetic multi-walled carbon nanotubes-Fe3C nanocomposite: Kinetics, equilibrium and thermodynamics, Chem Eng J, 210 (2012) 87-95.

[60] S. Chatterjee, M.W. Lee, S.H. Woo, Adsorption of congo red by chitosan hydrogel beads impregnated with carbon nanotubes, Bioresource technology, 101 (2010) 1800-1806.

[61] Q. Wan, L. Mao, M. Liu, K. Wang, G. Zeng, D. Xu, H. Huang, X. Zhang, Y. Wei, Towards development of a versatile and efficient strategy for fabrication of GO based polymer nanocomposites, Polym. Chem., 6 (2015) 7211-7218.

[62] X. Zhang, J. Ji, X. Zhang, B. Yang, M. Liu, W. Liu, L. Tao, Y. Chen, Y. Wei, Mussel Inspired Modification of Carbon Nanotubes Using RAFT Derived Stimuli-responsive Polymers, RSC Adv., 3 (2013) 21817-21823.

[63] Q. Wan, M. Liu, J. Tian, F. Deng, G. Zeng, Z. Li, K. Wang, Q. Zhang, X. Zhang, Y. Wei, Surface modification of carbon nanotubes by combination of mussel inspired chemistry and SET-LRP, Polym. Chem., 6 (2015) 1786-1792.

[64] Y. Shi, M. Liu, K. Wang, F. Deng, Q. Wan, Q. Huang, L. Fu, X. Zhang, Y. Wei, Bioinspired preparation of thermo-responsive graphene oxide nanocomposites in an aqueous solution, Polym. Chem., 6 (2015) 5876-5883. 